Journal of

Media, Culture \& Society

\title{
Audiences: A decade of transformations \\ Reflections from the CEDAR network on emerging directions in audience analysis
}

\begin{tabular}{|c|c|}
\hline Journal: & Media Culture and Society \\
\hline Manuscript ID & MCS-2016-464.R1 \\
\hline Manuscript Type: & Commentary \\
\hline Keyword: & $\begin{array}{l}\text { audiences, reception, audience research, transforming audiences, cedar, } \\
\text { new media }\end{array}$ \\
\hline Abstract: & $\begin{array}{l}\text { In this essay, I examine the ten years between } 2004 \text { and } 2014 \text { as a } \\
\text { transformative, if uncertain, decade for audience analysis, faced with } \\
\text { rapidly fragmenting media environments. Next, reflecting on the research } \\
\text { done by a } 14 \text { country network - Consortium on Emerging Directions in } \\
\text { Audience Research (CEDAR), funded by the Arts and Humanities Research } \\
\text { Council, UK - I examine the features of this decade of transformation, } \\
\text { paying attention to the intellectual markers that punctuate this decade and } \\
\text { make it stand out in the history of audience studies. I focus on four pivotal } \\
\text { axes of transformations which emerge out of the analysis conducted by the } \\
\text { CEDAR network and argue that these four represent significant ways in } \\
\text { which audience analysis has lived through an uncertain but exciting } \\
\text { decade. These axes are - audiences' changing coping strategies with } \\
\text { hyper-connected media, audience interruptions of media content flows, the } \\
\text { co-option of audience labour, and the micro-macro politics of audience } \\
\text { action. I conclude by locating this transformative decade } 2004-2014 \\
\text { against a longer backdrop of uncertain moments and periods of flux in the } \\
\text { field, arguing, that not unlike those points in time, now too, audience } \\
\text { analysis has reached a newer, more unknown, but very significant phase. }\end{array}$ \\
\hline
\end{tabular}

\section{SCHOLARONE ${ }^{\text {IN }}$ \\ Manuscripts}




\author{
Audiences: A decade of transformations ${ }^{1}$ \\ Reflections from the CEDAR network on emerging directions in audience analysis
}

\title{
Introduction
}

In this essay, I propose that the years between 2004 and 2014 have been a transformative, if uncertain decade for audience analysis, faced with rapidly fragmenting media environments, rapidly altering definitions of previously stable conceptual categories and an attempt amongst scholars to reposition the aims of audience research in the internet age. Next, reflecting on the research done by a fourteen country network - Consortium on Emerging Directions in Audience Research (CEDAR), funded by the Arts and Humanities Research Council, UK - I examine the features of this decade of transformation, paying attention to the intellectual markers that punctuate this decade and make it stand out in the history of audience studies. I focus on four pivotal axes of transformations which emerge out of the analysis conducted by the CEDAR network and argue that these four represent significant ways in which audience analysis has lived through an uncertain but exciting decade. These axes are - audiences' changing coping strategies with hyper-connected media, audience interruptions of media content flows, the cooption of audience labour, and the micro-macro politics of audience action. Across these, I interpret our long-standing categories of texts, readers and interpretive work, arguing that our understanding of these terms have now been fundamentally altered, thereby rendering these repertoires more, not less useful, than ever before. I conclude by locating this transformative decade 2004-2014 against a longer backdrop of uncertain moments and periods of flux in the field, arguing, that not unlike those points in time, now too, audience analysis has reached a newer, more unknown, but very significant phase.

The story of audience research has now been told by many scholars, some positioning waves and paradigms in the field, other inspecting key moments of crisis. This telling of the story of audiences seems to have served purposes both internal and external to the field. Internally, it has allowed scholars to distil signs of maturity in the field by arguing for the political and intellectual achievements made clear by each new paradigm and phase - this is clear for instance in Abercrombie and Longhurst's paradigms (1999) in audience analysis, followed by Livingstone's account of the participation paradigm (2013). This paradigmatic account was taken off by Abercrombie and Longhurst (2009), presenting a three-phase view of the field, from effects research, through encoding-decoding led research on resistant audiences, to the spectacleperformance paradigm of the contemporary mediascape, and carried into the contemporary moment by Livingstone's participation paradigm which suggests that "our new task is to understand the changing conditions of communication that, necessarily, underpin any and every form of participation" (2013, p 6). These paradigms have been all but unifying narratives. Martin Barker, for instance, found that very paradigmatic structure from Abercrombie and Longhurst close to a 'Hegelian teleology' (2006) suggesting instead that we focus on an often forgotten latter phase of gratifications research, and develop testable and verifiable ambitions for the field. Setting aside major differences in the narrative proposed by scholars, the telling of the story itself has, for instance, enabled newcomers to the field develop their agendas in the context of a relatively young field by

\footnotetext{
${ }^{1}$ I thank Tereza Pavlickova, Brita Ytre-Arne and Flavio Garcia da Rocha for comments on an earlier version of this draft, colleagues on the CEDAR network for contributing to the work I reflect on in this essay, and the Arts and Humanities Research Council for funding this project.
} 
locating within it key phases, trajectories and critiques, offering them devices with which to position their own work (Author Removed, 2014). The story has also been essential to offer ways out of prioritising a single dominant story of development in the field, which had to an extent seemed to keep the narrative static at the 'heyday' of audience analysis - this is evident in Livingstone's account of the canon of cultural studies (1998), the influence of more mass communications/sociology influenced entry points into the study of audiences following the account of the influence of Katz's personal influence work (2005), Barker's assertion that an adherence to Hall's encoding and decoding work "has hindered and indeed harmed our phase of audience research quite substantially” (2006), followed by Morley's reminders (2006) of the centrality of that text that lay at the very root of the canon above - Hall's encoding and decoding (1981). Externally, the attempt to develop these narratives of the field have responded to recurrent critiques - that of accumulating vast bodies of empirical work without adequately theorising (this was responded to by asserting that more work is indeed needed to de-Westernise the field), that of being over and done with in the age of networked media (the response to this last is the subject matter of this essay), and as recent conferences have shown, scholars seem to ask for both, a defined field, with clear boundaries for intellectual and institutional purposes, while others seem happy with the fluidity of the field's boundaries.

If we investigate the theorising at work within audience studies, critical cultural theory has made the most often noted and highlighted contributions, placing itself at the centre of perhaps concentric theoretical circles, and following scholars cited above, sociological, socialpsychological and mass communications entry points into the field remained perhaps on the outside of that centre. But at the roots of both, lay a longstanding interest in paired relationships of mutuality - between the interpreter and the text, whichever route one then took, to account for this rapport of mutuality (Author Removed, 2011). An infrequently used entry into this is through the hermeneutic wing of interpretivism which studies the interpretation of texts (Author Removed, 2011, 2012). If we use the interpretation of texts as our starting point, then, for each wave of 'new' media, bringing up new genres, new textual shapes, audience research needed to have paused and asked the question - are these ideas about texts and readers still of worth? The interpretation of something read as black words on white sheets must surely necessitate different modes of engagement than the audio-visual feast, comparatively speaking, of broadcast texts? This, however, did not accompany the gradual addition of televisual texts to texts in print. Audience lectures in classrooms continue to move very smoothly from Radway's Reading the Romance (1984) to Ang's Watching Dallas (1985). We move easily between Jyoti Puri's account of reading romance novels in postcolonial India (1997) and Mankekar's account of watching an Indian television show (!999). These studies all feature, quite comfortably together, in whichever week on an audience module they are expected to sit in. The listening of radio programmes, the watching of daytime televisions, and the reading of printed texts all seemed easily dealt with, without much pondering, with and within the text-reader metaphor, theorised differently, as I said above, through various points on the cultural studies-communication studies-psychologysociology spectrum.

But the next wave of newness, the advent of digitised, interactive, networked communication changed our comfort levels with texts and readers. New modes of engaging with genres (2003) seemed to be desperately in need of theorising as the hyper-reader clicking through links on an online article departed conceptually from 'traditional' readers flicking through pages in a library with a kind of rapidity, it would seem, that could not be mapped quite so easily on to parallel comparisons - between readers turning pages in a library and those turning channels on the 
remote at home. From the interest in the context and content of media reception which had helped converge these many modes of communication that had, in phases, entered the field, our attention was occupied very intensely, often even solely now, across many projects, by the form of mediated communication as a variety of questions started being asked of reading and readers in the context of use, many of them outside the field of audience analysis. These questions soon found reflection within the field as when Ytre-Arne queried the phenomenological differences between holding a magazine in one's hands and reading it online (2011), when Das carried hermeneutic concepts into fieldwork with Facebook users (2012), and when scholars from parallel generations met to discuss whether networked media had indeed spelt the end of audiences (Author removed, 2012). So, interactivity meant there was something so fundamentally altered, forever, for the readers and texts of audience research, that the smoothness with which we move from Radway to Ang, did not seem to be quite so easily replicated for another, similar, shift, both in the mode of communicative engagement and the generic shape of the texts in question.

\section{A decade of transformations}

In what follows, I argue that the decade 2004-2014, with blurred boundaries of course, on each side, heralded a new, transformative decade for audience analysis - one where the very form, and shape, of mediated communication so profoundly questioned concepts that had laid quite happily at the heart of all prior changes in mediated communicative conditions. I look for markers first, of the intellectual ripples, even waves, that these changes generated, finding them in articles, books, classrooms, international projects and as ever, in classrooms. One can locate within the rhetoric that dominated this decade, both uncertainty and excitement, both a desire to hold on to the repertoires that had been used till now, and a desire to look for new theorisations. I then move on to an analysis of this transformative decade as conducted by a 14 country network I direct (CEDAR - Consortium on Emerging Directions in Audience Research) that has spent time mapping these changes in the field, and I conclude by positioning this decade against a longer history of transformative moments in the field, all of which heralded a new phase in research, but none of which perhaps questioned, quite so strongly, our core conceptual devices.

This questioning had begun, outside of the field, before we began, so concretely, and so visibly, engaging in the business of conceptually and empirically getting into transforming audiences. Questions asked elsewhere as a precursor to this transformative moment in audience studies, included whether the hyper-reader is fundamentally different from the traditional reader (Calvi, 1999). What is the difference between reading and searching, or browsing? Is reading becoming more (or less) social, collective or collaborative than in the past (Thomas, 2005)? Are hyperlink pathways in digital genres to be understood via discussions from the earliest days of hypertext, even by juxtaposing for instance encyclopaedia pages and hyperlinks (Brügger, 2009)? One can anticipate, for instance, that new textual genres are to emerge (Kress, 2009), but how is one to know how these new genres necessitate new modes of interpretative engagement?

CEDAR was born in 2015, the year after the end of the European COST Action - Transforming Audiences Transforming Societies, so it is fitting to begin at the end of the decade in question, in the year 2014. Over four years, the action reflected a substantial amount of passionate interest in the changing field of audience research. For four years on the COST network people talked about how media environments had changed, thereby putting question marks around our previously stable employment of categories like texts and readers. People discussed how the ways 
in which people engaged with their media environments, to what purposes, and in which ways had all changed. And that - this reflected not only the affordances (Hutchby, 2001) of technologies around us, but the diverse ways in which people used the media in personal relationships, across distance and boundaries (Madianou \& Miller, 2011), for a variety of political and civic purposes (Carpentier 2011, Livingstone, 2013). Ultimately, as it stood at the end of that network in 2014- audience research could only be defined with great difficulty, for it had spread its roots amongst a variety of sub-fields and new fields, and yet - people continued to do (their own kind of) audience research.

At the other end of the decade in my mind, is the year 2004 - when the article - The Challenge of Changing Audiences was published where Sonia Livingstone asked, perhaps, on behalf of many in the field - What is the audience researcher to do in the age of the internet?. In the decade that passed between these two points, I suggest we lived through ten uncertain, and fantastic years- which began with people pondering about the future for researching audiences, with tentative suggestions for the future, including new terminologies both proposed (Bruns, 2009) and queried (Bird, 2013), new methodologies designed (Gauntlett, 2006) and questioned (Buckinhgam, 2009), and which concluded with countless new directions of inquiry for a clearly transformed field. This decade was marked quite clearly by the transforming audiences theme, which made itself visible in the form of conference titles as scholars gathered repeatedly at the University of Westminster in the UK, raising, initially, rather than answering, questions about audiences in transformations. Some asked how these transformations had manifested themselves in individualised patterns of television viewing (Bjur, 2009), some reminded the field that audiences were "not dead yet" (Bird, 2009), which was perhaps the most ambitious thing that could have been said of audiences in the midst of the many uncertainties brought by fragmenting media environments, some took steps towards carrying, quite literally, concepts from interpretations of linear texts into non-linear environments, either by connecting audience interpretation with digital literacies (Author removed, 2011), or, more widely by arguing for a link between the ambitions and purposes of audiences and literacies (Livingstone, 2008). A fresh wave of intellectual energy permeated the field with cross-media research (Schroeder, 2011), research on polymedia practices (Madianou and Miller, 2011) with the work done on media repertoires by colleagues in Germany (Hasebrink and Domeyer, 2012) and with a renewed energy to de-Westernise the lenses with which we looked at the field (Livingstone \& Butsch, 2013). The journal dedicated to audience and reception studies Participations showed articles and special sections which returned time and again to the transforming audiences theme (Schroeder et al, 2012). A meeting of three generations of audience researchers in Brussels, in 2012, showed precisely how three generations simultaneously had started pondering audience transformations, which then resulted in the themed special issue of the journal Communication Review (Das, 2013). Edited collections in the field all began speaking to theme of audience transformations (Carpentier, et al, 2015; Patriarche et al, 2015) emerging out of the COST Action's work, speaking of the need to 'revitalise' the field (Zeller, 2014). In a cross-generational conversation with my mentor, we argued that all need not change in the midst of this busy bustle of transforming audiences, suggesting a revised retention of our conceptual repertoires around texts and readers (Livingstone \& Das, 2012). Audiences had transformed - and with it, a decade that was busy with conferences, journal issues, articles, books and projects, all pondering the future of the field - had generated an amount of intellectual energy that had now begun scripting that very future.

\section{Four transformative axes}


So, when CEDAR began its work in 2015 , I found, that the question of interest was no longer whether audience research was dead, and the key assertion to be made was not that audience research is indeed, alive. These were questions and assertions that had over a decade we thought been taken care of. Instead, we set out to ask -what had happened over the past decade that was so transformative for audiences that it had effectively opened up countless new horizons of intellectual inquiry? This guided the first phase of our inquiry where our research has undertaken a year-long analysis of emerging themes about transformations in the past decade of research about audiences. This feeds into a foresight exercise about audiences in 2030, which is beyond the scope of this essay. In its first phase, CEDAR worked in six research clusters - methods and methodologies; text-centric audience research, audience experiences, participations and publics, invisible audiences; and design, interfaces and platforms. The network used qualitative, systematic, keyword based literature searches, analysing a shared database, using a common set of criteria about questions, methods, findings, accommodating field specific differences across clusters leading to an analysis of emerging themes published in 2016 as a themed section in the journal Participations (Author removed).

I reflect today, though, on four key axes of transformations that the network concluded, characterised, broadly speaking, these ten transformative years. These axes represent a grouping of numerous micro-trends that emerged from our mapping exercise and they speak of key axes of transformations in the field that have taken on pivotal roles for the field we argue, over the past decade. Our findings grouped into these axes inductively, as we worked bottom up through a very wide body of data. And these (intersecting) axes relate to audiences in their role as users of networked platforms, audiences as producers of content, audiences as people whose work is often co-opted by larger players and audiences and their capacities for action. Individually, each of these axes were shaped by and shaped the material and symbolic transformations that swept through audience research in these ten crucial years. Collectively, they represent the state of the art in a newly transformed field that has just begun an exciting new phase in its history.

Speaking to first axis above, CEDAR looked closely at how audiences of digital media are displaying a variety of strategies and competences to cope with increasingly complex, connected, intrusive media. We found that audiences are increasingly confronted with intrusive and automated digital media as evident from the very latest technologies. Audiences are developing new coping strategies (sense-making, appropriation) to deal with the formative and intrusive interfaces of digital media and much of this is research in fields outside audience studies. And, in the face of these changes, newer literacies are being developed, which shift attention towards the operating of digital media platforms and addresses their political and ethical implications. The work done by Ridder et. al (2016), and Mollen et al. (2016) proved particularly constructive within this axis.

Next, the network analysed how small, not just large, acts of audience production are punctuating existing flows of content. Here we concluded that audience practices increasingly include small acts of productive engagement with media content and that these small acts are now beginning to generate interest in the field. We suggested that only some productive practices more frequently supplement and broaden and challenge mainstream media content than others, and there is shift of focus from the lesson that we are not all producers now (Bird, 2013), towards distinguishing and finessing our understanding of different degrees of productive activity. We also found that there is an increased use of technology in story-telling by minority audiences and research is focusing on the political significance of the digital exchange of 
discourses and narratives. Key contributors to this axis were Pavlickova \& Kleut (2016), Dias \& Jorge (2016) and Zaborowski \& Dhaenens (2016).

Third, we suggest that acts of audience production are being sought, shaped and co-opted by larger bodies and the creative participation of audiences in glocalisation is being managed/coopted by global players. Transformations in media environments have meant that digital media platform design is shaping content and audience agency into computable data (metrification) and media industries are encouraging and appropriating audiences productive engagement for their purposes. The work of Vesnić-Alujević and Murru (2016) but also Mollen et. al (2016) have been particularly relevant here.

Our fourth and final axis of transformation involve audiences' emerging micro-politics finding ethical significance and shaping collective action. We find in this decade an emerging micropolitics of small-scale, everyday, individual actions are finding political/ethical significance. We find that listening is involving new modes of receptivity entailing constant switches between background attention to active reception, and research is investigating its political implications. And equally, we find that some audiences are channelizing their emotions and literacies into social movements and organized action. The work by Murru (2016) and Murru and Stehling (2016) have been relevant here.

\section{Conclusion}

The 1993 response to the 1983 Journal of Communication special issue 'Ferment in the Field' incorporated an article (Livingstone, 1993) asking for the convergence of administrative and critical research within the arena of audience analysis, for the pendulum had swung too far and too often between administrative and critical traditions. That was a critical moment for audience analysis, not just because of this debate, but because, then too, following a very exciting and busy period of research on interpretive diversity, the early critiques would soon begin coming in, about where it was all leading. A quarter century forward from there, today, the debates of relevance have progressed, as audience studies stand at the cross-media crossroads of our contemporary mediascape. But while, on the one hand, we have the intellectual markers of this transformative decade so clearly established, and a network producing analyses of precisely what forms these transformations have taken, on the other hand we have the media, including the popular press, where audiences continue to be spoken for, and industries, where audiences continue, following Ien Ang (1991) to be desperately sought.

If we begin tracing audiences in our field we find that the conceptual and empirical appearance of audiences and their interpretative work in the study of communication was a significant moment for communication theory because it helped balance a conversation on the impact of the media on an unthinking audience by irreversibly establishing an interpretative, critical and sometimes resistant viewer who decodes media content using a variety of symbolic resources. Cultural explorations of audiences informed questions of identity, communality, resistance and essentially, politics, thereby offering an inquiry into real audiences instead of reading off dominant messages in media discourses. At the level of the individual, we could now theorize the role of the reader (Eco, 1979) with appropriate empirical accounts of lived practices of interpretative work (Liebes and Katz, 1990), and, the interpretative activity of audiences now became visible in relation to a range of other societal roles of people, instead of being distinctly different from any of them. All of this remains relevant at a time, when, despite the commotion of these transformations, the project of active audiences 'is far from resolved' (Livingstone, 2015), and indeed, some audiences, as Kaun et al (2016) suggest in their work for CEDAR, are still, invisible. 
The bustling decade I have discussed in this essay was punctuated by hard questions asked of audience analysts about their relevance in contemporary communication studies. These questions were not simply posed rhetorically, in articles, and within the blurry, but nonetheless, comfortable boundaries of the field. These were questions asked face to face, at teaching planning committees, of many of us who wanted to retain 'audiences' in our module titles. These questions were asked outside of the field of audiences but within the wider field of communication studies, as some academic associations even 'lost' their audience divisions. This was hard, individually and collectively for colleagues who were researching their way through a rapid succession of changes, arguing for the retention of 'audiences' in academic organisations, trying to revise and retain audience modules in their teaching portfolios at a very transformative time. But these kinds of challenges were posed before, both in the field, and of the field. Perhaps not quite at the same scale, people doing reader-response studies were challenged about their uptake of the text-reader metaphor and its clear focus on interpretative activity as engaging in work that was too benign, or that was re-packaging gratifications research (Katz et al, 1973), that rapidly accumulating evidence of diversity and difference in interpretations was not really taking theory forward (e.g. Morris, 1988), that audience research in celebrating interpretative activity was celebrating limitless polysemy to the extent of ignoring textual power (e.g. Condit 1989), that this wave, phrased as the 'new revisionism' by Curran (1990), was merely rediscovering things discovered earlier, that audience research tends to use concepts such as meaning and sense making often without thinking about what is exactly meant by these terms (Dahlgren, 1998), or that this all neglected real issues of power (Corner, 1991). The difference perhaps has been that the latest wave of questions have had to do not with internal workings and achievements of the field, but rather the existence and relevance of the field itself.

If we read the hard questions asked in this transformative decade against the backdrop of the many critiques that have periodically punctuated the history of audience analysis, we may find hope in the fact that, for each wave of critique, a wave of responses were proposed, and audience studies moved on to the next phase. And part of the task is also, maybe, to recognise, as Mathieu et al reveal from their interactive interview exercise recently (Mathieu et al 2016), not everyone who does audience research today sits in a department of media and communications, and even if they do, they do not identify as audience researchers. In some ways, that might be a problem, at a moment when the field has had so many questions asked about its continued relevance. Or, perhaps, this might be part of a fruitful maturity of the field, where walls have given way and people have continued to research audiences in their own ways, in their own arenas.

\section{References}

Abercrombie, N. and Longhurst, B. (1998) Audiences: A sociological theory of performance and imagination. London: Sage Publications.

Ang, I. (1985). Watching Dallas: Soap opera and the melodramatic imagination. Psychology Press.

Ang, I. (1991). Desperately seeking the audience. London: Routledge.

Barker, M. (2006). I Have Seen the Future and It Is Not Here Yet ...; or, On Being

Ambitious for Audience Research. Communication Review 9(2): 123-141.

Bjur, J. (2009). Transforming audiences. Patterns of individualization in television viewing. (Livingstone, 2008). Sweden: University of Gothenburg 
Brügger, N. (2009) Website history and the website as an object of study. New Media \& Society $11(1 / 2), 115-33$.

Buckingham, D. (2009) Creative visual methods in media research: possibilities, problems and proposals. Media, Culture \& Society 31 (4), 633-52.

Butsch, R., \& Livingstone, S. (2013). Meanings of audiences: comparative discourses. London: Routledge.

Calvi, L. (1999) 'Lector in Rebus': The role of the reader and the characteristics of hyperreading. Paper presented at the 10th ACM Conference on 'Hypertext and Hypermedia: Returning to our diverse roots', New York.

Carpentier, N. (2011) New Configurations of the Audience? The Challenges of UserGenerated Content for Audience Theory and Media Participation, in V. Nightingale (ed.) The Handbook of Media Audiences, Malden, MA: Wiley-Blackwell, pp. 190-212.

Carpentier, N. et al. Eds. (2015). Audience Transformations: Shifting Audience Positions in Late Modernity. London Routledge

Corner, J. (1991) Meaning, genre and context: The problematics of 'public knowledge' in the new audience studies. In Mass Media and Society (pp. 267-84). London: Methuen.

Curran, J. (1990). The new revisionism in mass communication research: A reappraisal. European Journal of Communication 5 (2), 145-51.

Dahlgren, P. (1998) Critique: elusive audiences. In Approaches to Audiences: A reader (pp. 298310). London: Arnold.

Author removed

Author removed

Author removed

Author removed

Author removed

Dias, P. \& Jorge, A. (2016). Audience experiencing of emotions in the contemporary media landscape Participations 13 (1). Pp 431-445.

Eco, U. (1984). The role of the reader: Explorations in the semiotics of texts. Bloomington: Indiana University Press.

Gauntlett, D. (2007) Creative Explorations: New approaches to identities and audiences. London: Routledge.

Hall, S. (1980). Encoding/Decoding, Culture, Media, Language, London: Hutchinson.

Hasebrink, U., \& Domeyer, H. (2012). Media repertoires as patterns of behaviour and as meaningful practices: A multimethod approach to media use in converging media environments. Participations, 9(2), 757-779.

Hutchby, I. (2001) Technologies, texts and affordances. Sociology 35 (2), 441-56. 
Katz, E., Blumler, J.G. and Gurevitch, M. (1973) Uses and gratifications research. Public Opinion Quarterly 37 (4), 509-23..

Kaun et al (2016). In search of the invisible (audiences). Participations 13 (1). Pp 334-348.

Kress, G. (2003) Literacy in the New Media Age. London: Routledge.

Kress, G. (2009) So what is learning, actually? Social change, technological change and a continuing place for the school? Digital Literacies: Tracing the implications for learners and learning. Bristol. The third of four reports in the ESRC Seminar Series: 'The educational and social impact of new technologies on young people in Britain'.

Liebes, T. Katz E. (1990). The export of meaning. Cross-cultural readings of Dallas. New York: Oxford University Press

Livingstone, S. (1993). The rise and fall of audience research: An old story with a new ending. Journal of Communication, 43(4), 5-12.

Livingstone, S. (1998) Relationships between media and audiences: Prospects for future audience reception studies. In Liebes, T., and Curran, J. (Eds.),Media, Ritual and Identity: Essays in Honor of Elihu Kat: London: Routledge

Livingstone, S. (2004). The challenge of changing audiences: Or, what is the audience researcher to do in the internet age? European Journal of Communication 19 (1), 75-86.

Livingstone, Sonia (2006). On the influence of 'Personal Influence' on the study of audiences The Annals of the American Academy of Political and Social Science. Vol. 608, Politics, Social Networks, and the History of Mass Communications Research: Rereading Personal Influence (Nov., 2006), pp. 233-250

Livingstone, S. and Das, R. (2013) The end of audiences? theoretical echoes of reception amid the uncertainties of use. In Hartley, J., Burgess, J. and Bruns, A. (eds.) A Companion to New Media Dynamics. Wiley-Blackwell, Oxford, UK, pp. 104-121.

Livingstone, Sonia (2013) The participation paradigm in audience research. Communication Review, 16 (1-2). pp. 21-30. ISSN 1071-4421

Livingstone, S. (2015), Active Audiences? The Debate Progresses But Is Far From Resolved. Commun Theory 25: 439-446.

Madianou, M. and Miller, D. (2011) Migration and New Media: transnational families and polymedia, London: Routledge.

Mankekar, P. (1999). Screening Culture, Viewing Politics: an ethnography of television, womanhood and nation in post-colonial India. Durham: Duke University Press.

Mathieu, D. et. al. (2016). In dialogue with related fields of inquiry: The interdisciplinarity, normativity and contextuality of audience research. Participations 13 (1). Pp 462-475.

Mollen, A. et al. (2016). Intersecting audience activities: An audience studies perspective on the materiality of design, platforms and interfaces. Participations 13 (1). Pp 360-373.

Morley, D. (2006). Unanswered Questions in Audience Research. The Communication Review, 9(2): 101- 121. 
Morris, M. (1988) Banality in cultural studies. Discourse 10 (2), 3-29.

Murru, M.F. (2016). Listening, temporalities and epistemology: A hermeneutical perspective on mediated civic engagement. Participations 13 (1). Pp 392-491.

Murru, M.F. \& M. Stehling. (2016). The civic value of being an audience: The intersection between media and citizenship in audience research. Participations 13 (1). Pp 402-421.

Patriarche, G. et al. Eds. (2015). Audience Research Methodologies: Between Innovation and Consolidation. London: Routledge

Pavlickova, T. \& Kleut, J. (2016). Produsage as experience and interpretation. Participations 13 (1). 349-359.

Puri, J. (1997). Reading Romance novels in Postcolonial India. Gender and society, 11(4): 434-452.

Radway, J. (1984). Reading the Romance: Women, Patriarchy and Popular Literature. Philadelphia: University of Pennsylvania Press.

Ridder, S. et. al (2016). Challenges when researching digital audiences: Mapping audience research of software designs, interfaces and platforms. Participations 13 (1). Pp 374-391.

Schrøder, K. C. (2011). Audiences are inherently cross-media: Audience studies and the cross-media challenge. Communication management quarterly, 18(6), 5-27.

Schroeder, K. et al. Eds. (2012). Multimethod audience research. Participations 9 (2).

Thomas, S. (2005) Transliteracy - Reading in the digital age. A report on the 'Transliteracies' Conference held at the University of California, Santa Barbara, 7-8 June 2005. Available at www.english.heacademy.ac.uk/explore/publications/newsletters/newsissue9/thomas.htm. English Subject Centre Online Newsletter 9.

Vesnić-Alujević, L. \& Murru, M.F. (2016). Digital audiences' disempowerment: Participation or free labour. Participations 13 (1). Pp 422-430.

Ytre-Arne, Brita (2011): “'I want to hold it in my hands': Readers' experiences of the phenomenological differences between women's magazines online and in print", Media, Culture \& Society 33(3): 467-477.

Zaborowski, R. \& Dhaenens, F. (2016). Old topics, old approaches? 'Reception' in television studies and music studies. Participations 13 (1). Pp 446-461.

Zeller, F. et al. Eds. (2014). Revitalising Audience Research. London Routledge. 